menudo, de un estado indeterminado y sentimental a una determinación claramente estructurada.

A un cambio de rumbo en la Psicología ha contribuído también William Stern (Hamburgo), que ha creado a partir de reflexiones principalmente filosóficas, sobre la esencia de la vida, su psicología "personalista", cuyo pensamiento fundamental es, que todo suceder individual en la vida del alma sólo puede ser comprendido verdaderamente dentro de la unidad de la persona. Esta misma tendencia presenta la psicología de las profundidades de Freud y Adler. Si este último llama a su propia doctrina de la ciencia del alma "Psicología individual» quiere expresar con ello, que la totalidad del idividuo da la medida para la composición de los fenómenos animicos aislados.

Este cambio en la Psicología corresponde en la Biología-de la cual la Psicología es sólo una parte-al hecho de que en este momento el método mecanicista es combatido duramente por el vitalista, que pone su acento también en la unidad del carácter de la vida. Y si hoy, en la vida de los pueblos vemos al liberalismo y al individualismo, en difícil defensa frente a los poderes absolutos y universales, que como el bolcheviquismo y el fascismo tratan de aplastar por medio de su unidad y autoridad el derecho del individuo, queda de manifiesto que una nueva característica general imprime su sello a fenómenos aislados de nuestro tiempo. Y una vez más se hace evidente que la esencia de la vida espiritual es y sigue siendo una oposición. ¡Por eso nunca tiene razón un solo bando!.-A U G U S T O M E S S E R.

(Traducción especial para Atenea, directamente del Alemán por Luisa Frey Gabler y Juan Uribe Echevarría).

\title{
MATERIALISMO HISTORICO
}

\section{(Conclusión)}

UN estas categorías son, hasta cierto punto, arbitrarias y admiten de otras subdivisiones locales. Pero si dejamos a un lado la categoría, puramente hipotética, de los que se dedican exclusivamente a la recolección, y agregamos al final los estados industriales y comerciales, podemos aceptar como esquema aproximada las distinciones que hace Hahn. No obstante, estimamos que anda más cerca de la verdad Febvre, 
cuando dice: «Sería mejor, sin duda, proclamar simplemente lo que actualmente nos parece cierto: a saber, que no hay sino pocos pescadores, menos aun de cazadores o de cultivadores que se dedican exclusiva y continuamente a una sola y misma clase de actividad económica; pero que todos los hombres, en caso de necesidad, tienen varias cuerdas a sus arcos: que bajo el imperio de sus necesidades, los diversos tipos económicos se acercan los unos a los otros» (1).

Lo que debe observarse sobre todo, son dos cosas. Primero, no hay ningún paso obligado de una fase a otra o de un estado a otro, sino que aquí más que en ninguna parte se notan los saltos a que nos hemos referido. Segundo, los agricultores inferiores, que valiéndose de aquel instrumento primitivo, la azada, u otro más primitivo aun, como un palo aguzado, que se empleaba casi universalmente en América, lograban apenas sembrar un corto trecho de cereales o tubérculos, no tenían, como pretenden algunos viajeros, sociedades superiores a las de los pescadores, cazadores o pastores. Tampoco son éstos más incultos que la mayor parte de los agricultores rudimentarios.

Debemos notar que todas estas distinciones y clasificaciones son económicas. Se fundan únicamente sobre la manera cómo los hombres procuran la materia prima que les sirve para su alimentación y en eso se conforman con el marxismo, en cuanto se adcribe al factor económico los fundamentos de toda sociedad. Descuidan de toda otra consideración, pero, lo que hay de seguro es que el tipo económico no es lo mismo que el tipo social, el que no se establece sólo por la nutrición.

Hay pueblos que se diferencian profundamente por su hábitos domésticos, por sus caracteres morales, por su organización política, que son clasificados, sin embargo; bajo la misma rúbrica económica, la de pastores, por ejemplo, o de agricultores.

No es la diversidad de los alimentos que es la fuente de las distinciones entre los hombres, sino la diversidad de hábitos y de gustos que incitan a tales grupos humanos a buscar de preferencia cierta clase de alimentos y no otra. Es el conjunto de aptitudes, de gustos tradicionales, de ideas y de prácticas que los oponen unos a otros, aunque viven colindantes, pero sin mezclarse, el pigmeo cazador y el negro bantu, agricultor. Las condiciones del medio son iguales para ambos $y$, no obstante, pasan los siglos sin que ninguno de ellos modifique seria-

(1) Febvre, Lucien. Ob. cit. 
mente su género de vida. Pasa igual cosa entre pueblos de otra clasificación, en idénticas o parecidas condiciones. Veamos a los árabes y a los beduinos. Ambos son pueblos de pastores nómades, pero mientras que los primeros son polígamos, los segundos no conocen la poligamia. Existe entre ellos el infanticidio de las hijas y una tendencia hacia la poliandria, aunque predomina la monogamia. Los primeros buscan la familia numerosa, los otros prefieren restringirla.

En el Sahara, hallamos dos pueblos nómades, los moros y los tuaregs. Sus condiciones geográficas son comunes, un suelo parecido y un mismo clima son el patrimonio de ambos, en el cual son llamados a una vida paralela. Y, no obstante, se constata fácilmente las grandes diferencias' de lengua, de cultura, de costumbres, de traje y de armamento y un odio profundo les separa. Estos hechos que se podrían multiplicar, hacen meditar y demuestran que el factor económico no es el único en que hay que pensar cuando se quiere establecer la verdadera base de la estructura social y que tampoco es una consecuencia lógica suponer el paso obligatorio de un estado determinado a otro, sin tomar en cuenta los múltiples factores que pueden interrumpir o desviar semejante desarrollo evolutivo. Otra vez nos encontramos frente a la posibilidad de los saltos y este factor no ha sido debidamente contemplado por Engels, aun cuando en muchos de sus escritos ha insistido tanto en su necesidad.

Si hemos tomado el libro de Engels para demostrar estas enseñanzas, no ha sido por ningún motivo contrario a sus doctrinas políticas que en este caso no nos interesan mayormente, sino porque se oye hablar tanto hoy del socialismo en todas sus formas y en especial todo lo que se refiere al marxismo y nos ha parecido útil dejar indicados algunos de los puntos en que no ha seguido el método que él mismo ayudó a establecer.

Las observaciones que hemos hecho son igualmente aplicables a casi todos los historiadores, sociólogos y etnólogos de la segunda mitad del siglo pasado. Para nuestro objeto, cualquiera de ellos habría servido porque los errores que señalamos no eran propios de uno solo, sino eran casi universales en la época de que hablamos. Lubbock, Spencer, Tylor, Fustel de Coulanges, Waitz, Lippert, Ratzel, etc., etc., todos aceptaron los mismos datos, fórmulas, e interpretaciones y si varían en sus conclusiones, se debe en gran parte a los prejuicios de escuela y el sistema de construir apriorísticamente, sin fundamento sólido y comprobado.

$Y$, ya que hablamos de prejuicios, diremos que constituyen 
un defecto grande de la época en referencia y aun hoy la ciencia sociológica no ha podido desprenderse completamente de ellos, dejándose sentir con frecuencia hasta en el método del materialismo histórico, viciándolo.

Los prejuicios son de diversas índoles. Los hay religiosos, políticos, raciales, nacionales, de clase, ideológicos, etc., y muchas veces conducen al fanatismo, a la intolerancia $y$ a la intransigencia.

Con frecuencia son involuntarios y a menudo sus sostenedores no conceptúan que sean prejuicios, porque a ellos se les presenta como verdades. Así, por ejemplo, en la etnología, la escuela de Viena, encabezada por los Padres Wilhelm Schmidt, Koppers, Le Roy, Vros y otros, quienes adoptando el método histórico-cultural, han hecho un trabajo de investigación admirable, pero partiendo de un prejuicio religioso-el de la «revelación primitiva»-no han podido llevar al «último análisis * sus resultados. Separáronse por este prejuicio, de la escuela histórico-cultural de Berlín, preconizada por Graebner, Ankermann, Foy y otros. Admiten el método en todo lo material, pero lo cercenan en cuanto a su aspecto religioso. Aceptan la doctrina de la evolución y el largo lapso desde la primera aparición del hombre sobre la Tierra, pero para justificar su credo y su fe, tratan de probar que el hombre primitivo fué iluminado por una revelación divina y que la idea de un Ser superior, Dios y Creador, fué universalmente creída desde los tiempos más remotos de la humanidad, vaga e indefinida quizá, pero siempre presente. Estiman que los pueblos que no tienen semejante creencia se han degenerado posteriormente (1).

Indudablemente, ideas parecidas se han encontrado en algunos de los pueblos primitivos, pero es un argumento a priori, alegar que ellas han sido las más primitivas y que no se han adquirido después. Se puede concebir que aun cuando todas las condiciones materiales no se han evolucionado grandemente, que de la misma manera que ellas han recibido algunos aportes que no son primitivos, como el uso del arco y las flechas, puede haber pasado la misma cosa respecto de sus ideas y modo de pensar. En general se admite que las ideas religiosas comienzan con alguna forma primitiva del animismo. Pero en los últimos años, esta hipótesis ha tenido sus impugnadores. Preuss, Marett, Berth, Hubert y Mauss, Graebner y otros admiten una fase preanimística. Graebner, en la introducción de $\varangle \mathrm{El}$ mundo del hombre primitivo», dice: «La teoría del animismo

(1) Estas teorías se hallan detalladas en las obras del padre Schmidt: «La Révélation Primitives y \&L'origine de l'idée de Dieus. 
ha imperado casi sin limitación, durante mucho tiempo, en la etnografía, en la ciencia de la religión, e incluso en la historia de la filosofía, cuando ésta volvía los ojos atrás en busca de sus orígenes... Pero el cuadro varió cuando nuevos hechos negaron al animismo el derecho de representar la concepción cósmica de los pueblos más antiguos y más primitivos. En efecto, quedó averiguado que en pueblos muy primitivos-al parecer más viejos que las ideas animistas - se manifiesta una creencia mágica que nada tiene que ver con el animismo. Demostróse, además, que ciertas concepciones muy semejantes al monoteísmo existen no sólo en lós pueblos de alta cultura, sino también en estados muy primitivos de la humanidad..

Es evidente que cuando uno queda convencido de antemano de la verdad de una idea, existe la tendencia de interpretar los hechos en conformidad con dicho concepto, aun cuando las premisas sean insuficientes, como pasa en el caso del monoteísmo primitivo.

Los prejuicios políticos son casi tan comunes como los religiosos y en este terreno se colocan Marx, Engels, Morgan, Bachofen, Bebel, Plejano y otros, cuando tratan de probar el comunismo de los pueblos primitivos. Ven el comunismo en todo. Para ellos la promiscuidad sexual que presuponen no es otra cosa que el comunismo aplicado a la mujer, sin pensar que en tal caso, quitan los derechos de la mujer y así destruyen la idea céntrica del comunismo que es la igualdad de todos los individuos y no de clases aunque estas sean sexuales. Igual cosa pasa respecto de los supuestos matrimonios por grupos en que los derechos de los hombres se sobreponen a los derechos de las mujeres. Los trabajos colectivos de las agrupaciones de consanguíneos las interpretan por comunismo económico. No tenemos para qué volver a tratar estos puntos, ya que hemos demostrado su falsedad, incluso de no haber existido semejantes estados.

Los prejuicios raciales y nacionales son aparentes en la mayor parte de las historias, de los tratados de sociología y aun de etnografía. Tomemos, por ejemplo, las relaciones de las guerras de Napoleón. Sus causas, su desarrollo y sus resultados toman un giro completamente diverso y contradictorio, según las presenta un francés, un alemán, un inglés o un ruso. La ocupación de la India por los ingleses cambia de aspecto, según la explica un inglés o un hindú, aun cuando los mismos hechos fundamentales les sirven de partida.

La diferencia es mucho más pronunciada cuando se trata de la lucha de clases. Aquí los prejuicios llegan hasta cegar 
a los exponentes de las diferentes ideologías. La oligarquía, la burguesía y el proletariado nunca podrán ver su verdadera situación económica de una manera completamente imparcial, a causa de los fuertes prejuicios que anticipadamente se interponen y del fanatismo e intolerancia que estos mismos prejuicios despiertan en todas las partes interesadas.

Desgraciadamente todos estos prejuicios no parecen tales a los que los sostienen. Las más de las veces se presentan como verdades incontrovertibles, como grandes dogmas o axiomas y por lo general no existen argumentos capaces de destruirlos. Es común también, en las polémicas, de combatir un prejuicio con otro, la porfía con la intransigencia.

Es inoficioso advertir que el llevar semejantes prejuicios al terreno de la ciencia, produce resultados deplorables, especialmente, si como sucede a menudo, los investigadores de cierto renombre se dejan llevar por ellos. Aplicados a la historia y a la sociología, los prejuicios causan un gran daño al método del materialismo histórico, tanto más pernicioso cuanto más involuntarios sean, porque el lector que no es especialista, acepta y cree lo que encuentra en los libros y monografías, sin mayor examen. Esta costumbre de creer todo lo que se encuentra impreso es característico de nuestros tiempos. Nos acostumbramos a formar idea sobre lo que pasa en el mundo por lo que leemos en nuestro diario favorito y es muy corriente aceptar todas las opiniones expresadas en ellos, sin apreciar que no son más que la abogacía de cierto grupo de intereses determinados, y que otros diarios y peribdicos abogan por otras opiniones diferentes. Por otra parte todos tenemos nuestros autores predilectos, en los que tenemos más confianza que en los demás y todos tenemos la tendencia de aceptar sus conclusiones de preferencia de los de cualquier otro. En todo esto obran nuevamente los prejuicios involuntarios.

Los prejuicios, a menudo impiden ver o percibir la evolución que sufren las ideas y los conocimientos, con el trascurso del tiempo. Muchas veces nos aferramos a postulados ya caducos, porque están más de acuerdo con nuestros prejuicios y con nuestra ideología. Esto lo notamos en cuanto a las indiferencias del libro de Engels, aceptadas todavía por la mayoría de los marxistas como evangelio, y publicadas sin mayores comentarios en las sucesivas ediciones de la obra, aun en las más recientes.

Es indudable que todas estas influencias obran en detrimento del método materialista histórico y producen consecuencias contrarias a las que debemos esperar de el. En todo 
ello se puede observar una serie de finalidades en lucha de que habla Engels, lucha que impide, a menudo que el último resultante sea el que se auspiciaba. Todo esto lo explica muy bien Engels en la cita que presentamos al principio de este estudio.

Conviene ahora examinar un poco más de cerca la verdadera base en que descansa el materialismo histórico. Si nos atenemos a la definición que da Jorge Simmel (1), «es la vida económica, la organización y la actividad de los grupos llamados a producir y repartir los medios de existencia la que determina y forma la vida histórica en su conjunto; la política interior lo mismo que la política exterior, la religión lo mismo que el arte, el derecho lo mismo que la técnica».

«Lo que el materialismo histórico parece ofrecer primeramente, es una explicación psicológica de los acontecimientos históricos, según un solo y mismo principio... Es por esto que la designación de materialismo se presta a errores... Materialismo no podría significar, sino dependencia de la historia, en última instancia, de energías que no tienen nada de psíquico. Pero esto precisamente está en contradicción con el contenido mismo de la doctrina, que da a la historia motivo eminentemente psicológico... Lo que hace la grandeza de la doctrina es el deseo de mostrar a través de los contrastes y las transformaciones de la historia, el resorte que por su simplicidad elemental tiene las cualidades requeridas para representar la unidad en el mecanismo tan complejo de la vida histórica. La doctrina de que hablamos no es otra cosa que una hipótesis psicológica. Las acciones exteriores de los hombres se explican por hechos psicológicos que se pueden reducir en último término al interés por la producción y la reproducción de la vida inmediata».

Muchos de los que han criticado la doctrina, objetan la preponderancia que Marx ha dado a los factores económicos como base única de la historia. Alegan que cualquiera otra serie de valores históricos podrían haber servido igualmente bien como base para el conocimiento de la historia general del mundo. Consideran que todos los múltiples factores de tan diversa índole que entran en juego para producir los acontecimientos cuya relación coordinada llamamos historia, están entrelazados de una manera que hace imposible separar del encadenamiento ningún eslabón sin hacer peligrar toda la estructura. Es el encadenamiento total y no una de sus partes que constituye la

(1) Simmel, Jorge. Ensayo sobre el materialismo histórico. Atenea. Tomo XXII. Nos. $93-94$. Nov. Dic. 1932. 
historia de la sociedad humana a través de los tiempos. Y estos factores tienen los más diversos caracteres, materiales, fisio16́gicos, psicológicos, ideológicos, etc. Por las mismas razones con que se ha elegido la serie material para servir de base real, se puede elegir cualquiera otra serie, puesto que son inseparables. Cualquiera que se omita destruye inmediatamente la armonía y la realidad de los resultados y, por lo mismo, se podría estimár que esa serie era la que formaba la base.

Los marxistas alegan que todas las demás series son acondicionadas y en último análisis originadas por los factores económicos, pero no admiten que los factores económicos sean igualmente acondicionados y originados por el conjunto de otros factores que obran a la par con ellos. Y, sin embargo, es esto lo justo y lo real. Cada serie puede a la vez servir de base o acondicionarse a la superestructura, sin que el conjunto de la historia quede seriamente alterado, siempre que no se omita ninguna de las otras series. La elección de la serie base, depende en primer lugar del objetivo inmediato o de la finalidad que se persigue, sólo que en la práctica, es muy frecuente que dicho objetivo sea viciado por la introducción de uno o más de los prejuicios de que hemos hablado, como ocurre precisamente en la elección hecha por Marx, de la serie económica, la cual satisface más la necesidad de establecer sus doctrinas políticas sobre una base materialista. En cambio, el Padre Schmidt, Graebner y muchos otros eligen los factores psíquicos como base, para apoyar sus teorías sobre la universalidad de la idea de Dios, el concepto primitivo del Cosmos u otros fenómenos sociales, que ellos consideran de importancia y que modifican considerablemente el contenido material de la vida.

Los defensores del materialismo pretenden que los hechos económicos constituyen la fuerza motriz de todos los demás fenómenos sociales, los que se derivan directa o indirectamente de ellos. El hambre, es el gran impulsor, la necesidad de satisfacerla es la preocupación más imperiosa de la vida y las primeras actividades humanas son las que se dedican a buscar alimentos. Todo esto es efectivo, pero ¿hemos de considerarlo como un proceso mecánico que no admite ninguna variación volicional? Indudablemente que no, ya que vemos dentro de una misma área geográfica en condiciones iguales, una gran variedad de costumbres, prácticas, supersticiones, gustos y prohibiciones que modifican sustancialmente el modo de satisfacer estas necesidades.

Nos dirán que las necesidades siempre existen, independientemente de todo otro factor y precisan satisfacerlas de cualquier 
modo; que este modo está determinado por los productos naturales de la región, es decir, por el medio geográfico; que la elección de los productos alimenticios se derivan de la experiencia a fuerza de muchos ensayos y que todos estos factores son materiales y económicos.

Contestaríamos que siendo ciertos todos estos argumentos, existen y obran a la par de estos factores materiales, otra serie de factores psíquicos que restan de semejante solución simplista, para convertirla en compleja. ¿Por qué es que ningún pueblo primitivo utiliza todos los elementos naturales que sirven para la alimentación, dentro de la zona que habitan? ¿Por qué es que seleccionan algunos y dejan otros, aun cuando están apremiados por el hambre y aun por la muerte? ¿Por qué algunos pueblos, como los pigmeos del Centro de Africa, los siux, los patagones y otros, no comen pescado, cuando es abundante en los territorios que ocupan y a menudo pasan hambre cuando escasea su alimento acostumbrado? ¿Por qué los judíos no comen carne de cerdo? ¿Por qué entre la mayoría de los pueblos más primitivos, hay una serie de prohibiciones que impide que coman determinados alimentos, aun cuando sus vecinos se sirven de ellos? Ninguna de estas preguntas se puede contestar con razones materiales. Su resolución depende de ciertas condiciones psicológicas que no se derivan de las fuerzas productivas ni de las relaciones económicas, aun cuando modifican éstas.

En la etnografía, estos hechos son bien conocidos. Haberlandt condensa las ideas en los siguientes párrafos: «En todos los pueblos desde los más primitivos hasta las naciones privilegiadas de nuestros días, se observa una característica limitación eventual de los artículos alimenticios en forma de abstinencias. Las hordas errantes de los negros australianos, así como las tribus cazadoras del Brasil y los pueblos que practican una forma económica semejante, se abstienen durante algún tiempo o para siempre de comer determinados productos vegetales y animales, por razones que adquieren posteriormente carácter de impureza en las concepciones religiosas».

*Generalmente, la práctica de esta costumbre obedece a motivos de índole religiosa o mística. Se respeta al animal protector de la tribu, del cual descienden, según la leyenda, todos los habitantes; determinadas clases de animales son consideradas como poderosos hechizos; asígnase ciertas virtudes medicinales, especialmente a los artículos alimenticios vegetales y se considera este motivo como suficiente para renunciar a su uso en la alimentación. En etapas posteriores se supone que 
estos alimentos prohibidos son atributos de potencias y figura místicas, o se teme la impureza que procuraría su degustación. En este hecho se observa un ejemplo elocuente para el observador etnógrafo, cual es el de que los elementos culturales más rudimentarios de las etapas primitivas de la vida de los pueblos no se pierden, sino que se mantienen después de sufrir modificaciones o derivaciones, que a veces las hacen incomprensibles. $\gg$

Cuando levantamos el velo que encubre, para los civilizados, las acciones, supersticiones y creencias de los primitivos, penetramos en un mundo donde todo nos desconcierta. Aparentes absurdos por todas partes, ritos e ideas que chocan a nuestra razón y sólo se explican admitiendo que los primitivos piensan o perciben de modo distinto a como hoy lo hacemos nosotros. Estos ritos, ideas y modo de pensar influyen en todos los actos de la vida y destruyen o modifican la serie lógica de nuestros conceptos acerca de lo que debería suceder. En el caso que contemplamos, nos deja ver que el hambre no es el único impulso o fuerza motriz que acondiciona las leyes económicas y que éstas solas no pueden formar la base de la estructura social, ni son ellas exclusivamente que, en «último análisis determinan las fuerzas productivas materiales.

El hombre nace con su facultad de pensar, lo mismo que nace con sus necesidades economicas. Para satisfacer estas últimas, tiene que funcionar la primera. Si el comer es instintivo, no lo es la selección de los alimentos, lo que proviene de la experiencia, y la experiencia es el resultado de una serie de fenómenos psicológicos y fisiológicos. A su vez, dichos fenómenos son determinados en parte, por las propiedades del medio geográfico y en parte por las reacciones cerebrales que llamamos el pensamiento.

Tomando en cuenta todas estas cosas, podemos deducir que todos los actos materiales de la vida, menos los instintivos, factores obran de consumo y recíprocamente.

Otro punto en que la etnografía no puede estar de acuerdo con los intérpretes del materialismo histórico, es la separación que ellos hacen en la doctrina, de los factores constantes y los variables. Pretenden que no toda la vida humana tiene historia, sino sólo aquella parte que es susceptible de desarrollo. Pero esto destruye la realidad. En la vida misma, los factores constantes y los variables constituyen la unidad los hechos fisiológicos lo mismo que los materiales. Toda separación es arbitraria y da lugar a una selección que no es en ningún caso el reflejo real de la vida ni por consiguiente de la historia. 
Sobre este mismo punto dice Simmel: $*$ A cada instante los factores constantes y variables de la existencia constituyen una unidad indescomponible en la realidad. Es en los elementos constantes de lo corporal y de lo 16 gico, de las voliciones y de los sentimientos, de las impresiones sensibles y de las relaciones entre los individuos, es en esos elementos constante que para nuestro conocimiento no tienen "historia» que lo variable tiene su sustancia o sus accidentes; no se podría imaginar un estado al cual el pudiera avenir sin admitir esos elementos durables .

Para justificar esta separación, los defensores de la doctrina enuncian que la concepción materialista de la historia no pretende reducir a condiciones económicas hechos aislados de otra índole. Pero estos hechos aislados son reales y forman una parte integrante de la historia y frecuentemente en sí mismos provocan esa variabilidad histórica. El hecho de que un monarca no sea capaz de procrear hijos puede causar un cambio de dinastía e influir directamente en la historia de un pueblo, de una nación, de un continente ¿Cuántas veces ha sido modificada la historia por los amores de los gobernantes o de los grandes, sugestionados por los intereses o caprichos de las mujeres? Si la digestión de Nerón o de Heliógabalo hubiera sido normal ¿qué influencia no habría ejercido esto sobre los hechos reales de sus reinados y cuántos hechos históricos de aquella época habrían tenido otro desenlace?

No se puede alegar entonces que factores constantes, como la procreación, el amor, la digestión, etc., no influyen en la historia, cuando, a menudo, son ellos mismos los causantes de la variabilidad. Los instintos son también factores constantes y hemos visto de que manera pueden afectar los variables. En tales casos, el separar las dos series resulta en la separación de causas y efectos, entretanto que el objeto mismo de la historia es coordinarlos.

No vemos en todo esto más que un prejuicio obrando en favor de cierta tendencia ideológica. Admitimos la importancia de los factores de la producción y de las necesidades económicas; reconocemos que ocupan una posición predominante en la estructuración social, pero no podemos estar de acuerdo con la exclusividad de estos factores en la formación de la base histórica ni de la omisión de otros factores que también juegan un rol esencial, en el acondicionamiento de esta base.

Como dice Simmel: «Aquí, la doctrina rebaja el valor de su principio metódico, haciéndolo servir por un fin parcial. Este elemento variable, que por sí solo constituye la historia, es lo económico; excluyendo esta doctrina todos los otros, que cons- 
tantes en sí mismos, no varían sino cuando están sometidos a la influencia de éste. Tal aserción pone en plena luz hasta qué punto es arbitrario usurpar la directiva para la serie economica, cuando todas las otras series le están históricamente coordinadas. Es por eso que esta teoría me parece necesitar más una discusión psicológica que una discusión de hechos y me parece indicado explicarla por el motivo no teórico que sostiene toda la teoría materialista de la historia. Los representantes del materialismo histórico han sido inducidos, hasta aquí, a dar lo económico como contenido a las formas psicológicas, metafísicas y metódicas de su concepción de la historia, por la tendencia socialista y práctica. Y esto porque para una aspiración socialista, que como tal debe concernir a una gran masa, el interés económico es decisivo, porque no hay otro del cual se esté tan seguro de encontrar en cada elemento... Cualquiera que sean las diferencias que distinguen los individuos entre sí, habrá siempre un interés económico cualquiera que les será común. Una historia que tiene por punto de partida una convicción democrática y socialista será construída desde el punto de vista económico».

Admitiremos de una vez que sin el factor económico no sería posible la vida, pero es igualmente cierto, que, sin los factores psíquicos no habría sociedad o, si la hubiera, sería simplemente mecánica y constante como la de las abejas y las hormigas. La historia es la historia de la sociedad en su desarrollo y evolución y no la historia de la vida como función simplemente fisiologica, por tanto es imprescindible basarla sobre las funciones psíquicas a la vez que las materiales.

Entre los problemas psicológicos que han preocupado a los etnografos modernos, el de las ideas religiosas de los pueblos primitivos ha ocupado un lugar preferente. Hubo un tiempo en que se suponía que los pueblos más atrasados no practicaban ninguna forma de religión y que carecían de ideas religiosas. Hoy, sin embargo, se sabe que esto es un error y que por primitivos que fuesen los pueblos, nunca han faltado entre ellos los rudimentos de algún culto y aun entre los restos de la antigua edad de piedra se han encontrado objetos que parecen indicar la existencia de prácticas religiosas.

La falta de una definición universalmente aceptada para explicar las ideas de religion y magia, frecuentemente confundidas en un solo cuerpo de doctrinas, ha dado lugar a muchas controversias que en muchos casos han sido simplemente un desacuerdo sobre las formulas usadas.

Los hombres primitivos asumen, en general, dos actitudes 
respecto al mundo sobrenatural, el cual, desde los más remotos tiempos, despierta sus temores y su fantasía. Una de ellas es la persuación, petición o propiciación y la otra, la de coerción, constricción o compulsion. En muchos de sus ritos y observancias no es posible distinguir con claridad cuál de las dos actitudes está presente o dominante. En otros, las dos coexisten una al lado de la otra o se intermezclan. En otros aun, una sola es la única dominante.

Para nuestro propósito emplearemos el término religión para indicar una actitud persuasiva o propiciatoria hacia el mundo sobrenatural y el término magia para señalar aquellas actividades caracterizadas por una actitud coercitiva o compulsiva hacia el mismo mundo sobrenatural. En el sentido en que empleamos los términos, ambos incluyen tres elementos-intelectual, emocional y volitivo. En su fase intelectual, ambos implican o incluyen una fe o una creencia, una filosofía o ciencia. La filosofía o ciencia puede ser muy cruda, vaga e inconssistente, o puede ser muy clara, refinada y lógica, pero en todo caso existe alguna teoría de próximos o últimos causas o procesos. Por el lado emocional, tanto la religión como la magia participan en común de cierta deferencia, temor, afecto o reverencia hacia los seres o fuerzas con que tratan. En cuanto al elemento volicional, ambos incluyen una actitud práctica y discrecional para con las fuerzas o seres sobrenaturales. Este análisis es quizá demasiado simplista para los fenómenos complejos de la religión y la magia, pero en cuanto alcanza, permanece fiel a los hechos que describimos.

Las actividades religiosas pueden dividirse de muchas maneras. Las clasificaremos según la categoría de los seres que deben ser suplicados o propiciados, en cuatro clases principales: ánimas, o seres que alguna vez vivieron sobre la tierra como hombres; espiritus, seres menores que nunca fueron hombres, pero que pudieron ser fuerzas o fenómenos naturales; dioses, ánimas o espíritus que disfrutan de cierta preeminencia entre sus congéneres sobrenaturales, y el Ser Supremo que queda aislado y supremo o un ser cuasi supremo a quien se asigna el primer lugar en el mundo sobrenatural. De acuerdo con esta clasificación de seres sobrenaturales hallamos cuatro grandes tipos de religión: el manismo o culto de los antepasados; el animismo, o culto de los espíritus; el politersmo o culto de los dioses y el monoteismo, o culto de un Ser Supremo.

Monoteísmo, en su sentido estricto, es el culto de un Ser Supremo, concebido como el Creador único y dominador supremo del universo. Excluye y es intolerante de la creencia en 
y el culto de otros seres o fuerzas estimados como más o menos independientes en origen o en poderes del Ser Supremo. Entre muchos pueblos primitivos y civilizados, el Ser Supremo se concibe más bien como un ser cuasi-supremo, uno quien, de modo general, es el hacedor (en sentido material) del universo, pero no necesariamente de todo lo que en él existe; su culto no es exclusivo, sino admite y tolera los ritos y observancias manistas, animistas o mágicos y sus relaciones con las leyes morales es a menudo tan ínfima que puede considerarlas como no existentes.

Cuando hablamos de ánimas, espíritus o seres cuasi-supremos, éstos no deben concebirse en forma puramente espiritual o incorpórea. Empleamos aquellos términos para hablar de los seres invisibles, porque en las lenguas europeas modernas no tenemos otras que expresen ni siquiera aproximadamente, el concepto indígena. Ni alma, ni fantasma, ni sombra, ni espíritu interpretan exactamente la idea. En primer lugar, el primitivo no imagina ningún ser completamente espiritual. Materializa todas sus impresiones o imágenes mentales. Estas entidades pueden ser invisibles para sus ojos, sin embargo existen. Si existen, deben tener forma, luego son corpóreos. Las dota de volición y las imagina capaces de hacerse sentir en el mundo de los vivos. Generalmente las viste de sus propios sentimientos y atributos, pero, además, tienen otros atributos y poderes de que carecen los hombres. Su invisibilidad es voluntaria y cuando así lo desean pueden hacerse ver y sentir. El primitivo las pinta a veces con forma humana y a menudo como monstruos. Son todas enemigos potenciales más dispuestas a hacerle daño que bien. En general las teme y hace lo posible para aplacar o propiciarlas y de ganar, de cualquiera manera, su buena voluntad y protección.

Para el hombre primitivo, estos seres son reales. No los ve, pero se hacen sentir de mil maneras. Una avenida de agua borra su camino; una larga sequía arruina sus siembras o hace morir su ganado o aleja los animales de que depende su caza; un incendio destruye su hogar, una falsa pisada le troncha el pie; todos estos y muchos acontecimientos análogos le sucede a cada paso de su vida y para él no son accidentes fortuitos, que dentro de su concepción no existen, sino directamente provocados en su contra por dichas entidades.

Respecto de las ideas religiosas de los primitivos, no debemos perder de vista un hecho que es de primera importancia en la interpretación de los acontecimientos que forman la historia de tales pueblos, y es que casi siempre se entremezclan 
de una manera inextricable e intima en todas las acciones y preocupaciones de su vida diaria. Son religiones vivas, inseparables de su organización social y ocupan un lugar mucho más real en su vida que las religiones deístas de los pueblos civilizados.

La forma de religión que parece ser la más antigua era un tipo primitivo del animismo. Cierta escuela hablan de un período preanimista, en que existía sólo la magia, pero no creemos que esta opinión puede substanciarse, a pesar de la defensa de sus sostenedores. Siempre al lado de la creencia de los hechizos, de origen humano, existe un concepto de algunos seres sobrenaturales, invisibles, pero existentes y esto constituye el animismo. Aun los australianos, que se han citado tan a menudo como pueblo que existe en el estado preanimista, creen en seres sobrenaturales que producen los fenómenos naturales como las lluvias, los vientos, los rayos y el trueno. Hay hechos que ni ellos pueden atribuir a los hechizos ni a los poderes humanos. Esto en sí constituye una forma primitiva del animismo.

Los pueblos más primitivos creen que todo objeto tiene su espíritu propio, variando sus poderes en relación directa con su actividad o inercia. Los espíritus de las cosas inanimadas, salvo que estas fuesen anormales, no se temían tanto como los de seres vivos, ni los de los seres u objetos que se veían todos los días, tanto como los de cosas poco conocidas o extrañas. Estos se dotaban de poderes sobrehumanos en proporción a su poca frecuencia. Los desconocido o lo anormal era siempre potencialmente más peligrosa y debía temerse y evitarse en cuanto fuera posible.

Pero estas ideas no eran corrientes entre los pueblos cuya mentalidad y cultura eran más desarrolladas. Ellos creían igualmente en los espíritus, pero no ya que cada objeto tuviera su espíritu propio. En cuanto a la naturaleza y a los seres que la poblaban, se había formado distinto concepto. Los animales y otros seres vivos, al igual de los hombres, tenían espíritu, pero no así los objetos inanimados, aunque éstos podían cobijar, con ocasión un espíritu cualquiera. Pero para ellos existía otra clase de espíritu, que a falta de otra denominación, podemos llamar espiritu especifico, por cuanto representaba toda una especie. Por ejemplo, en vez de haber un espíritu para cada árbol, como antes, ahora había un espíritu de los árboles, de las fuentes, de los cerros, etc.

Entre los espíritus había muchos que eran las ánimas descarnadas de seres humanos y animales y otros muchos eran espíritus de la naturaleza y un sinúmero que no participaban de 
ninguna de estas características, sino que eran informes o monstruosos, según la imaginación de los distintos pueblos que creían en ellos. Por lo general eran todos malévolos o indiferentes y la principal preocupación de cada individuo era de precaverse de ellos y esto lo hacían de una variedad de maneras, muchas de ellas mágicas.

Pero algunos de los espíritus eran protectores de los hombres y eran sus seres tutelares. Principales entre éstos eran los de sus antepasados y en especial el primero de ellos, el fundador de la línea o estirpe. Venían en seguida los de sus tótemes o aliados de la familia o casta. Algunos de estos eran animales, otros, fuerzas de la naturaleza etc. Ocupando un lugar inferior estaban los espíritus que, por medios mágicos, habían captado y encerrado y que constituían sus fetiches. Una gran parte de dichos espíritus tenía su morada permanente o temporal en los objetos inanimados de la naturaleza circundante.

La preocupación de la mente indígena era la de procurar la buena voluntad de algunos espíritus y desvirtuar la malevolencia de otros que podrían perjudicarlos. Este resultado se lograba muchas veces por medios mágicos. La magia era para el primitivo una fuerza real y verdadera. Cada individuo tenía cierta capacidad para efectuarla y sus métodos eran más o menos eficaces según la persona. Cuando la magia personal no producía los efectos anhelados, el indígena recurría a algún mago o hechicero profesional o bien a la magia colectiva de una de las muchas sociedades o cofradías que existían en toda comunidad de alguna importancia. Se suponía que éstas podían influenciar ciertas clases de actividades y a menudo modificarlas o suprimirlas.

Las influencias mágicas no sólo se extendían a los espíritus que habitaban los objetos de su contorno, sino a aquellos también a cuyo cargo estaban los fenómenos naturales, como la lluvia, el granizo, la nieve, el trueno, el rayo, los temblores, el calor, el frío, etc. Todos los espíritus poseían atributos sobrehumanos, a veces sobrenaturales, y los hombres, por medios mágicos podían persuadir u obligar que se usasen estos poderes en su provecho, o para contrarrestar la malevolencia de los que obraban en su detrimento.

Si tomamos en cuenta todos estos hechos y examinamos la importancia que asumen en todos los actos de la vida de los pueblos poco civilizados modificando su modo de proceder, formaremos una idea más exacta de cómo las ideas o las reacciones psiquicas influyen fundamentalmente en la ejecución de 
acciones materiales aun las económicas, sin que las últimas puedan en ningún caso desprenderse de las primeras.

¿De qué manera ha podido la etnografía obrar en conjunto con el materialismo histórico? Desde luego, la etnografía comparada ha podido dilucidar que, a pesar de las divergencias de carácter y de idiosincrasia de los pueblos poco civilizados, debidas al clima, a la historia, y al medio físico, existen también caracteres generales comunes a todos esos pueblos que los oponen a todos los pueblos de la antigüedad clásica y del mundo moderno, que han alcanzado un grado superior de desarrollo. Desde el punto de vista de la religión, de la moral, del derecho; en el terreno económico, en lo que se refiere a la organización de la familia o del clan, por todas partes se descubren entre los no civilizados, sorprendentes semejanzas, que, al parecer, permiten ciertas conclusiones generales acerca de la evolución del pensamiento humano.

Pero, aun cuando hablamos de pueblos primitivos o no civilizados, no podemos suponer que por muy sencillos y más cerca de la naturaleza que se encuentren, que no hayan sufrido ninguna evolución y que en circunstancias favorables no pueden evolucionarse aun más. «Es poco lógico suponer, sin una demostración rigurosa que el desarrollo de la humanidad ha debido ser idéntico y rectilíneo en todas partes, adelantándose los más favorecidos un poco más por el camino del progreso, retrasándose, deteniéndose las demás desde las primeras etapas; todos empeñados, sin embargo, en un mismo camino cuyo trazado podría reconstruir en detalle el historiador, jalonando los puntos ocupados por los retrasados» (1).

No olvidemos lo que observa Graebner, que «cada vez vemos con mayor claridad que las formas culturales de los pueblos salvajes no representan fases distintas de una misma evolución, sino evoluciones múltiples, hererogéneas entre sís (2).

Si nos apartamos de los primitivos de la actualidad y remontamos el curso de la historia, veremos que en las más remotas fases de su larga evolución, los pueblos clásicos de la antigüedad, los semitas, los egipcios, los habitantes indígenas de la Hélade y de Italia, obedecían también a leyes mentales distintas de las que nos rigen a nosotros. Si comparamos estos resultados con las conclusiones de los etnógrafos, veremos que algunas de las características esenciales de la psicología de las menos civilizadas de las tribus actuales son las mismas que las de los pueblos arcaicos cuyo esfuerzo laborioso creará las gran-

(1) Kreglinger, Ricardo. Ob. cit.

(2) El mundo del hombre primitivo. 
des civilizaciones de la antigüedad. De este modo se puede hablar de la anterioridad y la sucesión de las etapas culturales, clasificar estas antiguas civilizaciones con relación a las demás y considerar las instituciones de la más antigua como iniciadoras de las más recientes. Esto hace resaltar la importancia de la etnografía comparada y la necesidad de incorporarla en la doctrina del materialismo histórico. Tampoco puede descuidarse de la arqueología, porque, si es cierto que su documentación es más escasa, que existe en ella muchas lagunas y que sus datos son, a menudo, difíciles de interpretar; sin embargo, su resultados positivos han sido de gran utilidad para la ciencia. Por medio de ellos se han podido resolver problemas que parecían insolubles y se ha podido establecer por sus investigaciones, que, en la antigüedad se hallaban pueblos muy parecidos a los primitivos de hoy, con semejantes costumbres y con una cultura material casi idéntica. De esta manera los investigadores modernos han podido convencerse que el estudio de los pueblos primitivos, actuales pueden poner en claro la historia inicial de las antiguas civilizaciones, completando el conocimiento de ambos. No basta estudiar una sola tribu o un solo pueblo, por más completo que sea el examen, porque con estos datos solos, no se podrá sacar conclusiones generales; es preciso reunir y comparar el conjunto de hechos recogidos en todas partes del mundo, en todos los pueblos y en todas las épocas, si queremos señalar las analogías y las divergencias, sin incurrir en grandes errores o contradicciones. $\mathrm{Y}$ aquí cabe una observación muy justa de Kreglinger, quien advierte que «las monografías consagradas a los no civilizados, son innumerables y proporcionan múltiples datos, hasta el punto de que el tebrico precipitado hallara facilmente entre, ellos hechos que corroboren sus doctrinas preconcebidas, sin contar que es grande la tentación de no tener en cuenta, sino aquellos que le favorecen» (1).

Pues bien, la experiencia nos ha demostrado que si se han tomado todas las precauciones indispensables, se pueden lograr resultados positivos que nos ayudan a comprender mejor la concatenación de la historia, tanto en su aspecto material, como en su esencia psicológica. Sin perder de vista las diferencias innegables, sin ceder al dogmatismo imprudente que en todas partes quisiera hallar ideas e instituciones idénticas, la etnografía ha sacado a luz analogías suficientes para que podamos hablar sin exageraciones de una mentalidad primitiva, distinta de la nuestra, cuyas características son las mismas hoy como en los tiempos más remotos.

(1) Kreglinger, Ricardo. La Mentalidad Primitiva, 1921. 
Sin tener muy en cuenta este diferencia de mentalidad no es posible comprender la manera cómo los conceptos de los primitivos se desarrollan, la que es casi siempre de una forma muy diversa de la que esperamos. Así resulta que, a menudo, las costumbres a que nosotros damos cierta interpretación, derivada de nuestra propia mentalidad, significan para el primitivo algo muy distinto. En el curso de este estudio hemos llamado la atención a varias de estas diferencias de interpretación, pero quedan otras innumerables que sería largo enumerar.

Se puede, sin temor de incurrir en erroreś, indicar otras dos importantes características de la mentalidad primitiva. Es en primer lugar colectiva. El hombre primitivo, es desde que nace, esclavo del grupo a que pertenece, el cual le impone sus costumbres, sus creencias, su género de vida, etc. Hasta en su matrimonio y en sus amores le limita a escoger mujer en ciertos medios determinados. Los miembros del grupo reconocen una solidaridad en todas las esferas de la vida. De las faltas del individuo se siente responsable toda la comunidad, la generación actual, como también las generaciones venideras. El grupo, pues, es el centro de todas las preocupaciones del primitivo.

La mentalidad primitiva es también esencialmente materialista, aun en sus ideas religiosas. El primitivo materializa todos sus pensamientos. Cada cualidad o atributo se le aparece como una cosa real, independiente del objeto mismo, pero formando parte de su contextura. Estas cualidades concebidas como materiales podrán abandonar el objeto, trasladarse a otra parte y aun ser adquiridas por el hombre, siempre por procedimientos materiales, como la manducación, acercándose simplemente a los objetos o seres que las contienen, frotándose contra ellos o por muchos medios. Todo individuo posee una materia semejante que representa el conjunto de sus cualidades. Esta materia impregna todo su ser y cada parte de él, cuyas propiedades persisten en todas ellas, aun cuando por cualquier motivo son separadas de su cuerpo. El miembro, el cabello, la uña, cortados, siguen particpando de estas mismas cualidades y el individuo sufrirá las mismas mutilaciones o afrentas que se infligen a éstos si caen en manos de algún enemigo. Al cortarse el cabello o las uñas, el primitivo guarda con el mayor cuidado, las porciones cortadas, en alguna parte que estima al abrigo de cualquiera tentativa malévola.

Esta cualidad material, propia del individuo, se extiende a todos los objetos de su uso personal, sus prendas de vestir, sus armas, sus adornos, etc., y aun a todas las huellas que deja a su paso, como las pisadas, las impresiones de sus manos o de 
cualquiera otra parte de su cuerpo y sobre todo se la considera intimamente ligada con su sangre.

En todas partes el primitivo cree en substancias, donde nosotros no vemos más que cualidades o propiedades. No hay para él, hombres sabios o fuertes, virtuosos o viciosos por sí. Existe la sabiduría, existen la fuerza, el vicio y la virtud, que pueden incorporarse temporalmente en un hombre, pero conservan su individualidad y pueden en cualquier momento abandonarle para instalarse en otra parte. Comer la carne de un animal fiero y valeroso es adquirir su valor; consumir el cadáver de un viejo de experiencia es adquirir su sabiduría. Sucede lo mismo con las otras cualidades individuales; pueden incorporarse a la persona y adquirirse por operaciones igualmente físicas, por el contacto cuando son objetos inánimes y sobre todo por la ingestión de las carnes que parecen ser el asiento cuando se tratan de seres vivos.

La substancia personal puede cambiarse. Entre muchos pueblos primitivos, incluso los antiguos araucanos y peruanos, para formar una alianza de amistad permanente, se solía extraer unas gotas de sangre de pequeñas heridas infligidas mutuamente, mezclarlas en una copa y beberlas, o bien cada uno lamía la sangre que brotaba de la herida del otro. Creían que así vivirían una misma vida y que se iniciarían relaciones de amistad indisoluble. Los jefes de tribus hacían o sellaban sus alianzas de igual manera, o bien participaban de una misma comida, - cambiaban regalos por los cuales trasmitían una parte de su propia personalidad. La costumbre de comer sal, tan repartida como garantía contra toda traición, no es más que una forma de esta práctica.

En los mismos principios descansan la sociedad y modifican, a veces considerablemente las fuerzas productivas y los factores económicos, sin que puede decirse que se derivan en «ultimo análisis> de estos, pues coexisten y obran de distinta manera, sin sujetarse al medio geográfico, género de vida o necesidad material, por más que sus manifestaciones sean materiales como también su concepción en las ideas del primitivo. Sin embargo sabemos que no son más que ciertas expresiones de la mentalidad, conceptuadas de una manera distinta a las nuestras.

-El grupo social es una unidad en la cual todos los miembros participan de una misma substancia. Ritos periódicos, sobre todo de comensalidad, mantienen y refuerzan estos lazos sociales; hechos todos de la misma carne (por la consanguinidad), todos se hallan animados por los mismos sentimientos, sienten iguales esperanzas, reaccionan unidos contra los peligros que 
los amenazan, se consagran al interés general. Conservan pura esta substancia social, preservarla contra toda contaminación, he aquí una de las preocupaciones esenciales de la política primitiva» (1).

Las comidas en común, especialmente el sacrificio y manducación del animal tótem por toda la comunidad, era uno de los mejores métodos de conservar intacta esta substancia social. Esta idea se conservaba en la antigua Grecia, entre los cretenses, los espartanos y los atenienses, quienes proclamaban que la república depende de estas comidas en común. En la antigua Italia, se excluía de la vida social y del ejército, aquel a quien una ausencia o una enfermedad hubiera impedido tomar parte en una de estas comuniones periódicas, en que se renovaban los lazos tribales. El forastero, por otra parte, es un enemigo potencial de quien se desconfía y la etiqueta que reglamente su recepción tiene justamente por objeto hacer menos temible su proximidad; no será nunca inofensivo hasta que por medio de una comida en común se haya incorporado la misma materia de que comparten los miembros de la tribu.

La creencia en dicha fuerza material personal, motiva un sinnúmero de ritos, costumbres y reservas que, sin conocer esta fase de la mentalidad primitiva, serían completamente inexplicables y nos parecerían ridículos. Sobre todo, auspicia ese estado que Marett (1) ha llamado preanimístico, el que, según Graebner se manifiesta en la creencia mágica y el uso de los hechizos.

Los primitivos ignoran la naturaleza y las causas de las enfermedades $y$, en consecuencia, las consideran lo mismo como la muerte, el resultado de un hechizo. De ordinario se cree que alguien ha introducido en el cuerpo del enfermo un objeto, casi siempre sólido y duro, en todo caso material. Por consiguiente, es preciso expulsar del cuerpo esta causa material de dolor y malestar. Y esto se consigue por medios también materiales, como frotaciones, masajes, succiones y a menudo por cortes efectuados en la piel o en la carne, sobre todo cuando está hinchada.

La estrecha asociación que hemos observado entre la cualidad personal del ser y todo lo que ha sido parte de él o de su propiedad íntima, es uno de los fundamentos de la magia simpática. Muchos pueblos primitivos creen que para perjudicar a un enemigo, se puede emplear una imagen o representación suya, o mejor aun un cabello, un pedazo de su vestido o de

(1) Marett, R. R. The threshold of religión. 1909. 
algo que ha estado en íntimo contacto con él. Como todas estas cosas participan de la cualidad personal de él, por reflejo, todo lo que se hace a una de ellas repercute en la misma forma sobre su persona. Para introducirle por hechizo trocitos de cuarzo en su cuerpo, basta hundirlos en sus pisadas. El objeto que utiliza para representar a su enemigo, a quien tuesta al fuego o ahoga en el agua, a fin de producirle la enfermedad o la muerte, es el sustituto, en su imaginación es el enemigo, y para él, la asociacion es perfecta. De esta manera, cualquier objeto, aunque elegido arbitrariamente, puede reemplazar a la persona a quien se quiere hechizar. La representación queda en la imaginación del primitivo, tan fuertemente asociada a esta expresión sentimental, que el objeto inanimado se identifica, para él, completamente con el enemigo. De aquí que sea posible ejecutar la acción hostil como acción mágica, aun cuando no hay ningún objeto material intermediario. Así, algunas tribus apuntan y blanden en dirección de la víctima un hueso o madera aguzada, al tiempo que maldicen e invocan el género de muerte que quieren para su enemigo.

La creencia en los hechizos se extiende a la caza. La costumbre de dibujar en el suelo una imagen del animal o ave que se quiere cazar y alancear esta imagen, garantiza una buena cacería. El mismo resultado se alcanza representando por la mímica una cacería o la pieza que se va a cazar. La misma manera de discurrir se encuentra en otras formas de hechizo. La asociación aparece clara en el hecho de que los wakelbura de Australia dan de comer a sus niños la lengua de una lagartija para que aprendan a hablar rápidamente. La costumbre extendida por toda la Australia, del endocanibalismo, descansa en parecidas ideas. Puesto que al comer a un semejante se asimilan las propiedades del comido-fuerza juvenil, prudencia, etc. se comen a menudo, niños y también ancianos.

La religión de los primitivos es también una aplicación de estos mismos principios y en este respecto tenemos algo que decir del concepto de mana, nombre que ha figurado tanto en las discusiones sobre los orígenes e historia primitiva de la religión, desde fines del siglo pasado. La palabra misma, como también la primera y más importante descripción del concepto, nos llega desde la Melanesia (1).

Sin embargo, en muchas otras partes del mundo se encuentran vigentes los conceptos fundamentales que encierra, aunque difieren en detalle de un pueblo a otro. La idea misma es en mu-

(1) Codrington, R. H. The Melanesians. 1891. 
chos respectos vaga, nebulosa y elusiva, por no decir contradictoria e inconsecuente. Pero si dejamos a un lado estas nebulosidades e inconsistencias y diferencias locales, la idea céntrica de mana parece ser la de una energía más o menos impersonal y mística, una especie de poder preternatural, inmaterial, pero dinámico, que se adhiere a las cosas o puede ser apropiado por los seres y que produce efectos más allá que los límites ordinarios de los procesos naturales y de los poderes humanos.

El concepto de mana en su forma variante y local, aparece como una tentativa incoherente, no muy clara ni consistente, por parte de los metafísicos y científicos primitivos, de concebir una explicación racional de la manera cómo la magia produce sus resultados sobrenaturales. El concepto es muy extendido en el mundo, pero no tenemos ninguna prueba que haya sido universal, aunque Kreglinger dice que se ha hallado en todos los pueblos sobre la superficie entera del globo.

Al estudiar el cosmos, el primitivo encuentra que ciertos objetos o fenómenos poseen entre otras cualidades, un vigor una vitalidad, una fecundidad anormales y advierte una substancia que les confiere estos poderes poco comunes. Poder te mible y misterioso, funesto a todos los seres débiles, que sean incapaces de resistir a su acción. Poder saludable también para aquellos que pueden utilizarlo y beneficiarse personalmente de todas las virtudes que se suponen en el.

Este poder o mana de los melanesios, que se llama wakan entre los dakota, manitu entre los algonkines, tinh entre los anamitas, lunyensu entre las tribus de Africa Central, kami entre los japoneses, es la numina de los antiguos romanos, el brahma de los hindúes, el pneuma de los estoicos. Es una influencia que no es física, pero que sólo se manifiesta en los cuerpos materiales, sin hallarse nunca, sin embargo, ligado a ninguno de ellos de una manera permanente e inseparable.

Este poder misterioso, cósmico, e impersonal, que se manifiesta en todos aquellos objetos que inspiran cierta veneración, se trasfunde en el hombre también por los sentimientos de la inquietud, de respeto, de temor que experimenta en ocasiones solemnes. Circula a través de todas las cosas, los astros y los elementos, los dioses y los hombres; es el principio de todo lo que se mueve, de todo lo que vive, de todo lo que se agita, poder del cual no se hallan igualmente dotados todos los seres, pero que se incorpora particularmente a la persona de los sacerdotes y los hechiceros, o bien en objetos que el hombre venera y que precisamente a causa de su presencia considera como divinos, poder que por otra parte no es personal, sino una materia inorgánica. 
Era este mismo poder que los israelitas llevaban en el arca, al tocar el cual, cay6 fulminado Oza.

Por todas partes en las religiones primitivas hallamos el mismo concepto-nada de dioses personales, sólo el mana. La noción de esta fuerza o poder, el materialismo religioso, es una aplicación, entre muchas, de ese carácter fundamental de la mentalidad primitiva, que la lleva a suponer substancias, más o menos materiales, donde nosotros no vemos más que propiedades o cualidades.

Fuerza misteriosa, el mana aniquila al hombre que se acerca impunemente a los cuerpos que la tienen, como hemos visto en el caso de Oza. Tendrá que mantenerse a distancia de ellos; para él son tabu. La muerte, la enfermedad, la ceguera le amenazan cada vez que falte a las reglas que le son impuestas a este respecto. Pero si logra el hombre inmunizarse contra este materia misteriosa, si mejor aun, logra utilizarla en su provecho dirigir conform a su interés las fuerzas formidables de que se siente rodeado, gozará a su vez de poderes ventajosos, dominará la naturaleza y la someterá a sus fines (1).

Aquí entonces, tenemos un concepto, bastante, sino universalmente repartido entre los pueblos primitivos, que, por medio de los tabu, restricciones, prohibiciones y temores, circunda la vida de aquellos hombres y obra como un freno sobre sus deseos, sus pasiones y aun sus necesidades. Es otro de aquellos factores psíquicos que modifican y limitan el libre ejercicio del factor económico, en ciertas ocasiones. Aun cuando el primitivo lo conceptúa en forma material, porque materializa todos sus pensamientos, se trata de un fenómeno psíquico que no proviene de ningún factor material, pero que, sin embargo, influye considerablemente en el establecimiento de la verdadera base de la estructura social. Motiva en gran parte una serie de ritos y observancias; es una de las principales causas de la iniciación de los púberes y de muchas ceremonias que, sin una comprensión de esta condición psíquica, nos parecen absurdas y futiles. Es uno de los principales fundamentos de la magia y explica los éxitos y fracasos de los magos, cuyas operaciones son generalmente medios para influir o someter este poder en algunas de sus muchas manifestaciones.

Con todo, esta creencia en el mana no constituye una verdadera religión, pero es una de las causas iniciales de todas las religiones y como tal, un factor de suma importancia en el estudio de la mentalidad indígena.

(1) Kreglinger, Ricardo. Ob. cit. 
En este ensayo hemos tocado someramente algunos de los problemas y fenómenos sociales que la etnografía moderna nos presenta y que, hasta ahora, no han sido incorporados de una manera eficiente en la doctrina del materialismo histórico. Sin embargo, es imposible coordinar los conceptos acerca de los orígenes históricos de los pueblos y de la humanidad, sin tomarlos bien en cuenta. El omitir cualquiera de ellos da otro contenido, necesariamente falaz, a la historia. Ha sido costumbre de los historiadores, dar muy poca importancia al estudio de la organización social de los pueblos primitivos. Han aceptado, sin mayor examen, ciertos postulados, generalmente especulativos, sobre la evolución de la sociedad de los pueblos considerados por ellos como salvajes, y los han copiado unos de otros, para encuadrarlos como una especie de introducción obligada a sus tratados, iniciando el verdadero estudio de sus temas con las civilizaciones clásicas o preclásicas, sin preocuparse mayormente de la evolución anterior de la humanidad. Se han encontrado con una serie de fenómenos sociales que cada uno ha traducido a su modo y en conformidad con las teorías que deseaba exponer. Según la manera de traducir dichos fenómenos era también la interpretación que daban a las supuestas formas sociales primitivas, casi siempre establecidas a priori, sin una previa investigación de los hechos fundamentales.

Hoy, no es procedente continuar así. La etnografía ha salido en ayuda de la historia, proporcionándola un enorme acopio de datos y hechos fidedignos, que presenta una nueva base para toda la estructura histórica y no hay disculpa para no utilizarlo. toda la estructura histórica y no hay disculpa ninguna para no utilizarlo. La aplicación de estos datos a la reconstrucción de los fundamentos sociales, da un nuevo contenido a toda la historia de la sociedad, cualquiera que sea el aspecto estudiado. Esto lo hemos visto en cuanto al aspecto económico y es igual mente exacto si los aplicamos a cualquier otro.

Es con el objeto de señalar la diferencia entre los conceptos especulativos del siglo pasado y los más positivos y objetivos de hoy, que hemos criticado la obra de Engels, porque la mayoría de los marxistas, hoy más numerosos que nunca, como también los partidarios del materialismo histórico, todavía aceptan dicho libro como clásico inatacable, reproduciéndose nuevas ediciones, sin ninguna modificación. No culpamos al autor los errores que se hacen aparentes en el. Es difícil ver cómo, en el tiempo en que escribió, pudo haber llegado a conclusiones más exactas, pero, en la actualidad, necesitamos algo más moderno y más en línea con los conocimientos actuales. 
En cuanto a la aplicación de las enseñanzas de la etnografía a la doctrina del materialismo histórico, sólo la afecta en algún grado, en cuanto al rumbo imprimido a ella por los principales escritores marxistas quienes la han utilizado más con el propósito de afianzar una ideología que en buscar las verdaderas bases de la historia, sin prejuicios. Sin embargo, lo que sorprende es que los fundamentos mismos de la doctrina expuesta de una manera dispersa en las obras de Marx y Engels, han sufrido muy poco por las críticas y abusos a que han sido sometidos. Con ligeras modificaciones quedan firmes, a pesar del gran avance de las ciencias y de las ideas, si les quitamos todo el envoltorio de sofismos usados por los que han tratado de utilizarlos para determinados fines.

Como método, el materialismo histórico es también excelente, toda vez que se lo aplica sin prejuicios y $\sin 1$ la intención de valerse de el para comprobar teorías preconcebidas. Sin duda debe valerse, en todo caso de las más recientes investigaciones de la etnografía y aun de la arqueología, la que correlaciona la vida de los antiquísimos pueblos, largo tiempo desaparecidos, con los cuya historia nos es más conocida. También va sin decir que los conocimientos actuales y las interpretaciones que hoy damos a los fenómenos sociales, serán mañana caducos y habrá que renovarlos. Toda evolución, lo que hoy parece ser verdad, mañana se estima falso así que es peligroso dogmatizar y sólo se pueden presentar los hechos que se conocen al momento y las deduciones que se cree poder sacar logicamente de ellos, sin preocuparse mayormente de lo que tendrá que decir el futuro.- $\mathrm{R}$ I C A R D O E. L A T C IH A M.

Santiago, Abril 30 de 1933.

\section{«REDESCUBRIMIENTO DE DON JUAN"}

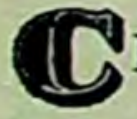

IERTOS escritores sepañoles no han podido ver con total indiferencia, que una de tlas creaciones más geniales de su literatura-Don Juan-haya sido tratada sin miramientos por plumas autorizadas.

Escritores de muy diversas tendencias como Ortega y Gasset y Pío Baroja, han puesto muy en claro, que don Juan representa algo más que el personaje clínico y el mito sexual de que nos hablan Marañón y Ramiro de Maeztu. 